The University of San Francisco

USF Scholarship: a digital repository@ Gleeson Library |

Geschke Center

2015

\title{
Work System Theory as a Platform: Response to a Research Perspective Article by Niederman and March
}

Steven Alter

University of San Francisco, alter@usfca.edu

Follow this and additional works at: http://repository.usfca.edu/at

Part of the Business Commons

\section{Recommended Citation}

Alter, S. (2015) "Work System Theory as a Platform: Response to a Research Perspective Article by Niederman and March", Journal of the Association for Information Systems, in press

This Article is brought to you for free and open access by the School of Management at USF Scholarship: a digital repository @ Gleeson Library | Geschke Center. It has been accepted for inclusion in Business Analytics and Information Systems by an authorized administrator of USF Scholarship: a digital repository@Gleeson Library | Geschke Center. For more information, please contact repository@usfca.edu. 


\title{
Work System Theory as a Platform: Response to a Research Perspective Article by Niederman and March
}

\begin{abstract}
This article responds to "Taking the Work System Theory Forward" (Niederman and March, 2014), a JAIS research perspective article about an article on work system theory (Alter, 2013e). The research perspective article recognizes value in the work system approach, suggests that WST is not a proper theory, and suggests areas for related theory development.

After summarizing the main ideas in WST, this article explains disagreements between Niederman and March (2014) and Alter (2013e), hereafter called N\&M and the WST article, regarding what WST is and what WST should become. It notes that N\&M interprets basic ideas in WST differently than those ideas were defined in the WST article. It notes that N\&M's critique of WST is anchored in issues about the nature of theory, especially a preference for Gregor's Type 4 theory. It explains that WST is a special case of general system theory, and as such should not and cannot take the form of a theory that expresses relationships between independent variables, moderating variables, and dependent variables. Next it explains why the WST article called WST a theory when it might have been called something else, and also why the development of WSM was not treated as a design science research project. The concluding section responds directly to N\&M's title, "Taking the Work System Theory Forward" by explaining that WST is becoming a platform for applications and extensions in IS and within and across a number of disciplines. It illustrates that view using examples under five categories.
\end{abstract}

Keywords: work system, work system framework, work system life cycle model, theory in IS

\section{Preface}

This paper is a response to a JAIS research perspective article entitled "Taking Work System Theory Forward" (Niederman \& March, 2014). That article identifies issues and provides suggestions related to my JAIS article, "Work System Theory: Overview of Core Concepts, Extensions, and Challenges for the Future." (Alter, 2013e). My article presents work system theory (WST) as the basic ideas underlying the work system method (WSM), which was developed over many years through iterative improvements across many different versions. That article also explains extensions beyond the core concepts, positions WST in relation to other approaches and theories, evaluates progress to date related to WST, and identifies challenges for the future.

This article contains many references to Alter (2013e), my 2013 article on WST, and to Niederman \& March (2014) since it is a response to the latter article, which itself is a response to the former. For ease of reading and interpretation, this article uses "the 
WST article" to refer to Alter (2013e) and N\&M to refer Niederman \& March (2014). All other references are handled in a standard manner.

The N\&M research perspective is generally supportive of the work system approach but is critical of aspects of WST as a theory. My general impression of the main points in $\mathrm{N} \& \mathrm{M}$ is as follows:

- $\quad \mathrm{N} \& M$ sees potential value in the work system approach.

- Many of N\&M's comments and suggestions about WST actually refer to the work system approach or WSM due to inconsistencies in definitions in the WST article versus definitions in N\&M.

- $\quad \mathrm{N} \& \mathrm{M}$ sees WST as an atheoretical model rather than as a theory.

- N\&M implies that something called WST should be a Type 4 theory (Gregor, 2006) that explains and predicts. Furthermore, WST should be evaluated using criteria for a Type 4 theory, including importance, novelty, parsimony, appropriateness of theoretical level, and falsifiability.

- Many of N\&M's suggestions for "taking WST forward" are related to possibilities of theory development (in the style of positivist Type 4 theory) that might emerge from the ideas in the work system approach.

This response argues that a narrowly focused positivist theory addressing some parts of the domain of WST might fit better with certain views of theory per se, but would have much less potential value than the current formulation of WST. It is organized as follows:

1) Brief summary of the content of the WST article. This section provides context for the main ideas in this response to the critique by N\&M.

2) Divergent views of what WST is and how to move WST forward. This section starts by showing that N\&M interprets basic ideas in WST differently than those ideas were defined in the WST article. While WST is a system theory that necessarily does not have independent and dependent variables, N\&M's critique of WST is anchored in a preference for Gregor (2006) Type 4 theories that are stated in terms of independent, moderating, and dependent variables. Those differences lead to strongly divergent views of how to move WST forward.

3) Previously unexplained background and motivation of the WST article. This section explains why WST was called a theory and why it was not explained as an instance of design science research.

4) Conclusions and a question about the primacy of theory. This section briefly summarizes conclusions about the best path for moving WST forward. It ends by questioning the academic IS discipline's commonly held belief that theory is better than other types of knowledge. 
5) WST as a platform. This section extends the discussion of what WST should become. It summarizes my current view that WST is becoming a platform for many future applications and extensions in IS and within and across a number of disciplines. It presents the examples under five categories. Deferring the presentation of many examples until after the other three sections makes it easier to follow the flow of those sections.

Voice and tone. Addressing those topics directly and honestly calls for a personal and colloquial tone that bypasses some of the (in my opinion) formulaic, often excessive, and sometimes misleading packaging that suffuses many journal articles and conference papers. Aspects of the response to $\mathrm{N \& M}$ explain personal reasons for undertaking a difficult project and personal speculations and ambitions that energized the effort. Useful results were produced, even though parts of the research could not be "justified" based on the type of backward looking, provenance-oriented rationales that are common in IS research articles, such as the assumption that progress must be based on previously published theory.

\section{Brief Summary of the Content of the WST Article}

I arrived at three general beliefs based on eight years of experience in a successful manufacturing software firm, plus insights from publishing and using four editions (1992, 1996, 1999, 2002) of an IS textbook:

1) Most business professionals could benefit greatly from an organized systems analysis and design method that they can use directly for their own purposes, with or without the help of IT professionals or consultants.

2) The IS discipline had not yet succeeded in providing and disseminating that type of method.

3) The wide availability of that type of method would substantially increase success rates for system-related projects, would improve business/IT alignment at many levels, and would provide significant opportunities for IS research that is inherently valuable and is likely to have recognizable real-world impacts.

As those beliefs emerged, I started developing what I called the work system method (WSM). I tried out different versions of WSM during an iterative process of developing a method that typical MBA and Executive MBA students could use effectively and efficiently. As the number of versions increased, it became more difficult to explain exactly what WSM was. Other frameworks and methods that evolved over time have faced similar issues (e.g., activity theory, soft system methodology, and the creation of UML out of several different approaches and through several versions).

Three things remained almost constant over the development of WSM to date: the definition of work system, the work system framework, and the work system life cycle model. I say "almost" because some of the terminology changed incrementally over the years. Two examples are small changes in the work system framework. The first was a change from "business process" to "work practices" in order to emphasize actual practices rather than documented processes that may or may not be followed in reality, The second was a subsequent change from "work practices" to "processes and 
activities" because my MBA students seemed to find the term "work practices" awkward to use effectively in presentations and written work.

Definition of WST. One of the main goals of the WST article was to define and organize the different parts of the work system approach for thinking about systems in organizations. Pages 75-86 of the WST article define the term work system, the two central frameworks, and each term in those frameworks. As shown in Figure 1, WST article says that WST consists of the following:

1) the definition of work system

2) the work system framework, a static view of the work system as it exists during a particular time interval when it retains its identity and integrity even though it may change slightly through small adaptations, workarounds, personnel changes, and even unintentional drift (e.g., Pentland et al., 2011)

3) the work system lifecycle model, a dynamic view of how work systems change over time through a combination of planned and unplanned change.

Almost all significant work systems in organizations use IT and therefore are within the domain of the IS discipline. Most work systems should not be viewed as information systems or IT systems, however, because most of them are not about IT or about processing information, just as work systems that use electricity should not be viewed as electricity systems because they happen to use electricity.

1) Definition of work system: a system in which human participants and/or machines perform work (processes and activities) using information, technology, and other resources to produce specific products/services for specific internal and/or external customers.

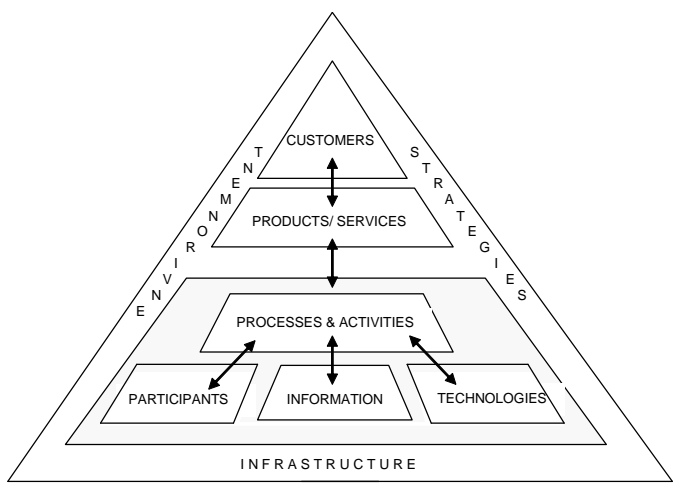

2) Work system framework

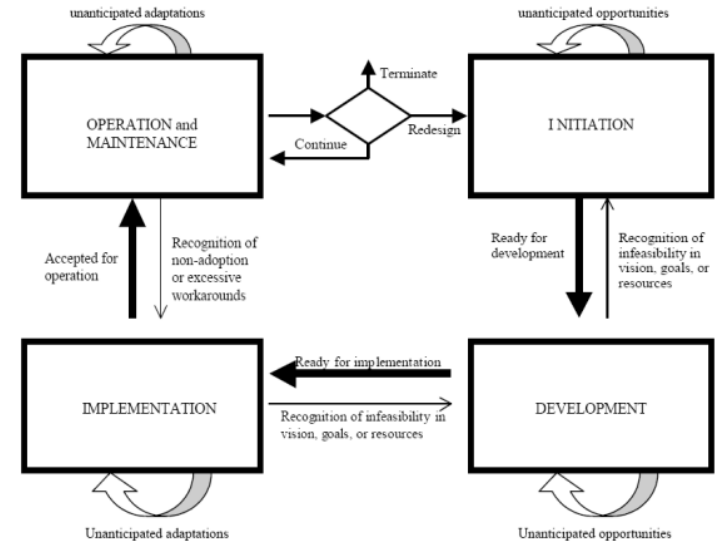

3) Work system life cycle model

Figure 1. Three components of work system theory (Alter, 2013e)

Definition of WSM. The various versions of WSM apply WST but are not part of WST. They are WST applications designed to help business professionals, IT professionals, students, and researchers think about current and proposed work systems. The term 
method in WSM refers to a systems analysis and design method for creating or improving work systems that almost always are IT-enabled and may or may not be information systems. Thus, WSM is not a research method related to building or testing an explanatory or predictive theory. The various versions of WSM all involve at least the following steps:

- identifying the main problems or opportunities that launched an analysis,

- identifying the smallest work system that exhibits those problems or opportunities.

- summarizing the "as is" work system using a work system snapshot, a stylized one page summary that includes customers of the work system, products/services that it produces, processes and activities, participants, information, and technologies in the work system

- evaluating the work system's operation using measures of performance and other factors,

- drilling down further as necessary, e.g., by using typical Six Sigma tools such as root cause analysis, swimlane diagrams, and Pareto diagrams,

- summarizing proposed changes by producing a work system snapshot of a proposed "to be" work system that will probably perform better,

- describing the likely improvement in work system performance.

Initial versions of WSM were meant for use primarily in the initiation phase of a systemrelated project as a way to help in defining the work system that is to be improved and in explaining a proposed improvement. Focusing on work systems rather than hardware/software configurations is a step toward overcoming an ingrained tendency to think about system-related projects as little more than producing software to satisfy requirements and installing it on computers. WSM is not a complete system development method, however, because the guidance that it provides does not include explicit methods for development and testing of software. On the other hand it may support those activities and may lead to better system development results because it leads to clarity about the business purpose, scope, and intentions of system-related projects.

Extensions of WST. The extensions of WST are various concepts, frameworks, methods, and theories that are based on WST and that can be used whenever appropriate for thinking about work systems in general, about categories of work systems, and about specific systems in organizations. Published extensions of WST that will be mentioned later include work system principles, work system design spaces, various versions of a work system metamodel (illustrated later in Figure 2), a theory of workarounds, a taxonomy of work system interactions, and a number of extensions related specifically to service and service systems.

Earlier versions of WST. After recognizing the need to articulate the conceptual core of work system approach, starting around 2008 I explored different initial versions of WST. I brought an original version that covered all five of Gregor's types of theory to the 2010 JAIS Theory Development Workshop. The almost unanimous response was that the draft's depiction of WST was unclear about the boundaries of WST and about whether WST would expand whenever any new idea related to WST was proposed. After working on a number of drafts of the WST article, I concluded that the 3-part definition of WST and the distinction between WST, WSM, and extensions of WST could address a number of goals simultaneously: 
- $\quad$ provide necessary clarity about what WST is.

- overcome confusion resulting from many versions of WSM

- provide a basis for explaining progress to date in developing the work system approach.

- provide a central core that forms the basis for deeper examination that could reveal and articulate many distinctions, nuances, special cases, applications, and extensions.

In my opinion the WST article succeeded in defining WST and in clarifying how it is distinct from its application in WSM and also distinct from various extensions of WST. I hope it will succeed in overcoming inconsistencies and confusion resulting from previous publications mentioning different versions of WSM and extensions of WST. At minimum, the effort of writing the WST article created a way of explaining WST, WSM, and extensions that is much clearer and easier to understand than previous explanations.

\section{Divergent Views of What WST Is and What WST Should Become}

This section discusses divergences between N\&M and the WST article regarding what WST is and what WST should become. It starts with different interpretations of what WST is. It discusses how differing views of the nature of theory lead to differing views of what WST should be. Later, Section 4 will return to an issue underlying much of the discussion in this section, i.e., whether the academic IS discipline treats theory, especially Gregor (2006) Type 4 theories, as somehow better or more important than other types of knowledge, such as information, concepts, frameworks, and methods.

\subsection{Differing Interpretations of What WST Is}

As illustrated in Figure 1, the three components of WST include a definition of work system, a basically static view of a work system as it exists during a particular time interval and a dynamic view of how work systems change over time. Even though a three-part definition of a theory is atypical, WST includes all three parts because all three are important for understanding, evaluating, and improving work systems.

Defining WST precisely was important for several reasons. A central goal was to overcome confusions related to the iterative development of WSM. As mentioned above, an essential commonality of the various versions was their basis in a core of ideas that the WST article identified as WST. Another reason for defining WST precisely was the reaction to an initial draft of the WST article that was presented at the 2010 JAIS Theory Development Workshop. The almost unanimous response was that the draft's depiction of WST was unclear about the boundaries of WST and whether WST would expand whenever any new idea related to WST was proposed. After working on a number of drafts of the WST article, I concluded that the 3-part definition of WST and the distinction between WST, WSM, and extensions of WST was the most practical way to provide necessary clarity about what WST is. 
N\&M defined WST, the work system framework, and the work system method differently from the way those terms are defined in the summary in the first section. The following comments identify some of these differences.

N\&M's view of the WST article. The abstract of N\&M says that the WST article "proposes the work system theory (WST) as the transformation of previously developed information system (IS) artifacts: the work system method (WSM), the work system framework, and the work system life cycle (WSLC)." In contrast, the WST article states that WSM is not a part of WST, but rather is an application of WST. Also, the WST article does not transform anything. Instead, its contributions are based on updating and clarifying each of three previously existing components.

N\&M's view of WST. A footnote on N\&M, p. 347, says that WST is "the set of generalized statements and principles underlying the work system approach." It is not clear which generalized statements and principles are meant to be included in that definition. For example, it might or might not include some of the 24 work system principles that the WST article identifies as an extension of WST.

N\&M's view of the work system framework. The same footnote says that the work system framework refers to "the description and organization of the components used to represent a work system." In my view, the work system framework identifies and organizes nine specific elements of a basic understanding of a work system. The graphical representation of the relationship between the elements is shown in Figure 1 and has been published many times. The names of several of the elements evolved slightly over the years (as noted earlier).

The work system framework is only one of several summaries of components used to represent a work system. Several versions of a work system metamodel (discussed in Section 5) are extensions of WST that provide a more detailed representation of components of a work system. Like an online map with zooming capabilities, the less detailed work system framework and the more detailed metamodel are related to each other and can be used for some of the same purposes, but are designed to be especially useful for their own particular purposes. A service value chain framework (also discussed in Section 5) adds a service perspective that is not apparent from either the work system framework or the work system metamodel(s).

N\&M's view of WSM. The same footnote says that WSM is "those processes and procedures by which the components of a work system are identified, analyzed, designed (re-designed), and implemented." That comment is unclear about whether the ideas in WST are the basis of WSM. It is more accurate to say that WSM is a particular approach to identifying, analyzing, and designing a work system based on WST. The WST article, p. 90, says, "Comparing WST with various system development approaches is beyond this paper's scope because WST is not a system development method just as WSM is not a system development method, but rather, an adaptable method for analyzing and designing work systems."

The WST paper, p. 90, recognizes that "a number of other theories and perspectives provide their own unique lenses related to systems in organizations. ... [It] compares WST briefly with seven very different perspectives, all of which are relevant to one or another aspect of understanding systems in organizations." For example, while noting that "work systems are viewed as sociotechnical systems by default, WST does not 
follow the tradition [in sociotechnical systems theory' of separating social systems versus technical systems ... Instead, it views the social and the technical as part of a single system." (p. 91)

Is the definition of WST unclear? After checking the WST article again, I think that the definition is clear but that a reorganization of an early draft may have contributed to a somewhat fuzzy impression of WST at the beginning of the published article. Figures 3 and 4 in the published article (pp. 117-118) initially appeared nearer the beginning of several early drafts to clarify the distinction between WST and its applications and extensions. Later those pages were moved to an appendix at the end of the article to improve the article's flow. I think that was an appropriate goal, but it may have brought the disadvantage of deemphasizing the precise definition of WST. ${ }^{1}$

\subsection{Differing Views of the Nature of Theory}

Much of N\&M's critique of WST is anchored in issues about the nature of theory. N\&M applies Weber's (2012) view, which

"restricts the term 'theory' to the Type 4 in Gregor's (2006) taxonomy, which reflects both explanation and prediction. He explains that the elements of theory are (a) constructs measured as precisely as possible, (b) tested relationships among these constructs, and (c) a defined boundary in which these relationships apply. He states that theory must both predict and explain the phenomena under consideration."

The WST article takes a different approach. It mentions long-standing debates in the social sciences and in IS about the nature of theory but avoids engaging that issue fully because doing so would have been beyond its scope. Instead, it justifies calling WST a theory by citing Schatzki's (2001) view that a theory is an abstract account. I had learned about that view from Feldman \& Orlikowski (2011), an article by two widely recognized scholars who used that view of theory as the basis of their discussion of practice theory.

The list of IS theories in the "Theories Used in IS Research Wiki" (Larsen et al., 2014), which is available in the Research section of the website of the Association for Information Systems, includes many sets of concepts that are called theories in the IS discipline even though they would not qualify under Weber's (2012) criteria. Examples include actor-network theory, behavioral decision theory, contingency theory, critical realism theory, evolutionary theory, feminism theory, game theory, general systems

\footnotetext{
${ }^{1}$ The WST article explained WST as follows: The second page of the WST article (p. 74) says that definition of work system "leads to the two central frameworks in WST: the work system framework and work system life cycle model." Instead of repeating that statement by saying that WST consists of the definition and the two central frameworks, the first page of the section on WST (p. 75) focuses on positioning, starting by saying that WST "is an integrated body of theory that includes a Type 1 analytical theory (the work system framework) and a Type 2 explanatory theory (the work system life cycle model), which in combination give the basis of a Type 5 design theory (WSM)." The section on extensions of WST introduces work system principles, work system design spaces, and a new work system metamodel, saying, "This paper treats these extensions as useful developments that are outside of the core of WST." (p. 87). The 3 part structure of WST appears most clearly in Appendix 2, Figure 4 (p. 118), which places the work system concept, work system framework, and work system life cycle model inside of a central oval. The accompanying text says, "WST is represented by the central oval, in which arrows say that the work system concept led to the work system framework and work system life cycle model, all three of which have existed for over a decade and now can be seen as forming the conceptual basis of WSM. Figure 4 also shows more recent extensions that build upon those ideas." (p. 119)
} 
theory, institutional theory, sociotechnical theory, soft systems theory, and structuration theory. Other widely cited IS-related theories that do not appear in the Wiki and that would not qualify include activity theory, coordination theory, and practice theory. Many theories discussed in other fields also would not qualify. Examples from mathematics include group theory, number theory, perturbation theory, and set theory.

In other words, WST qualifies as a theory under the Schatzki and Gregor approaches to theory and is every bit as much a theory as many other abstractions that are called theories in the academic IS discipline. Section 3 will return to the issue of whether WST should have been called a theory and a related question about why theories should be preferred to other types of knowledge. For now we continue with the question of what WST should be.

\subsection{Differing Views of What WST Should Be}

The WST article (p. 90) explained that WST is a special case of general system theory. "WST is basically a special case within GST that focuses on systems in organizations. GST provides basic concepts for thinking of situations as systems, such as boundary, environment, input, output, transformation, and state. WST reframes those concepts in relation to systems in organizations, and therefore is much less general than GST. In relation to WST's domain of application, a shortcoming of GST and various short lists of GST concepts (e.g., open system vs. closed system, subsystem, form, function, boundary, environment, interface) is that the short lists do not provide enough guidance to be helpful in many specific types of situations."

The title of N\&M is "Moving the Work System Theory Forward." N\&M seems to see WST as presented in the WST article as a somewhat amorphous group of concepts, frameworks, models, and methods. N\&M suggests that the work system approach seems potentially useful in general (e.g., comments on pages 348, 351, 352, and 355) and that it might become a steppingstone for theory development.

WST as an opportunity for theory development. N\&M (p 350) says,

"by Weber's (2012) definition, the WST would likely be viewed as an atheoretical model. The WST does not present clear, measurable, and indisputable constructs in the same sense as "the construct ease of use can be associated with the construct amount of use"....We propose that the WST, even if viewed as "atheoretical" by this definition, is ... a possible precursor to the sort of theory that would satisfy a Type 4 categorization. We see the WST as presenting the IS field with an opportunity to engage in a process of theory development and building."

N\&M seems to imply that concepts in WST such as participants and information are not clear, measurable, and indisputable. All of the terms in WST are defined clearly. The measure of whether someone is a participant is whether that person performs one or more of the activities in a work system. Similarly, the information in a work system is the information that the work system uses or produces. These are simple, straightforward ideas that are directly relevant to understanding and analyzing systems. The WST article defines the other basic concepts in a similar fashion. Regardless of whether WST is an atheoretical model or a theory, there are no benefits in trying to convert a system theory like WST into a positivist Type 4 theory containing constructs resembling ease of use 
and amount of use, the two constructs mentioned in the above quote from N\&M, p. 350 . In fact, those two constructs are associated with one of the many relationships included in the work system metamodel that is an extension of WST (shown later as Figure 2).

Purpose of WST. N\&M (p. 350) says that the purpose of WST is unclear.

"We find that the purpose of WST per se is not clear in its current formulation. After many readings, we do not see clear and general statements about what WST is intended to accomplish."

I am sorry that WST's purpose seemed unclear. As stated previously, WST's primary purpose is to serve as an organized kernel of ideas for understanding how systems in organizations operate and how they change over time, regardless of whether IT plays a significant role.

Note that there is no claim that WST is the best possible kernel of ideas for that purpose. The WST article, p. 99, suggests extending its comparison of WST and WSM with other theories and methods "to try to develop hybrids that are better than existing theories and methods. For example, a detailed look at accounts of real world applications of SSM, ANT, organizational routines, practice theory, and activity theory could identify synergies that lead to better theories and methods."

Should WST become a Type 4 theory? N\&M (p. 351) seems to want to convert WST into a positivist Type 4 theory instead of a system theory:

We can envision a formulation of WST such as: those responsible for business process management will create better (less expensive, more reliable, more effective, etc.) systems using the WST in their system development practices than those not using WST. We think this is what the current formulation proposes, but, if we are wrong, it is at least partly due to this element of the theory not being clearly specified.

WST is the formal identification and organization of a system view that is useful for many purposes. Transforming WST into a Type 4 theory saying that using something like the current WST ideas is better than not using those ideas serves no apparent purpose because much of WST's value is in clarifying, organizing, and extending ideas that have already been used in many different ways by many instructors and researchers. Furthermore, I don't see why a statement that a particular method or set of ideas is useful should be called a theory. Instead of calling something like that a theory I would call it either a claim of efficacy or the results of an evaluation of efficacy. If claims of efficacy were called theories then we would have UML efficacy theory, BPMN efficacy theory, portfolio theory efficacy theory, and so on.

In addition, there are no apparent benefits in replacing WST with a Type 4 theory that has the same name. WST was developed as a special case of general system theory that provides a system-oriented lens for understanding a broad range of important situations. Like the lens of a camera or a camera as a whole, it has a number of features and characteristics and can be used for a variety of purposes and at quite different levels of care and expertise. There are plenty of valid questions about the circumstances for effective use of WST, of various versions of WSM, and of various WST extensions. Those questions are not part of WST, just as questions about conditions for effective usage of a camera are not part of the camera. 
Combining issues that should be viewed separately. N\&M combines several valid issues that should be viewed separately. One valid issue is whether WST is a "proper" theory and how it might become a seed for theory development in the IS discipline. A completely different issue is how to maximize the value of a set of ideas that already have been used by many researchers and by many hundreds of MBA and Executive MBA students. In my opinion, maximizing the value of WST is related to finding new applications and extensions and is unrelated to whether it should be more like a Type 4 theory.

While I see no reason to convert WST to a Type 4 theory, the WST paper explicitly noted the desirability of testing the usefulness of WST and of other theories and methods. The following is the tenth item on a list of "next steps in research" on pages 98-99: "Formulate a Type 4 theory for explanation and prediction (Gregor, 2006) related to insights from WST for system modeling techniques in general. Related propositions would say that modeling techniques that encompass all or most of the work system framework will provide more comprehensive, and hence better analysis than techniques that focus on only one or several work system elements." This item is not about changing the nature of WST. Rather it is about developing and using a separate Type 4 theory to investigate whether WST's content matters in practice.

In addition, the work system framework itself contains a number of assumptions related to internal alignment. Those assumptions could be treated as propositions to be tested empirically in the manner of a Type 4 theory, but this would not involve or necessitate changing the nature of WST as a special case of a general systems theory." The WST article notes, "the arrows inside the work system framework say that the specific elements of a work system should be in alignment. For example, the knowledge, skills, interests, and motivation of the participants should fit with the processes and activities in the work system. Conversely, the processes and activities should be appropriate for attributes of the participants. ... Similar alignment issues apply for all pairs of elements that are linked by arrows." (p. 79)

What is the dependent variable? Perhaps motivated by a preference for Type 4 theories, N\&M tries to build on a claim in the WST paper (p. 79) that "the work system framework is a useful basis for describing and analyzing an IT-reliant work system in an organization because its nine elements are part of a basic understanding of a work system." N\&M, (p. 351) says,

The assertion that the WS framework is "useful" adds an element of purpose, and thus falsifiability, to the WST. However, the terms "describing and analyzing" present a variety of possible interpretations. Is WST's purpose to present a tool aimed at clarifying business processes or, ultimately, to aid in building better systems? Implicit in the theory is explanation that one could build better work systems ... because of the more thorough and diversified analysis induced by the use of the WS framework in whole or in part. In other words, are "thoroughness and diversification" the dependent variables of the theory, or are these moderating variables for an ultimate purpose of a different dependent variable: making better systems?

The comment about dependent or moderating variables is a detour away from the best way to question a claim that information, participants, products/services produced, and 
six other elements of the work system framework are part of a basic understanding of a work system. It is easy to identify illustrative examples showing that a basic understanding of a work system should include all nine elements. For example, there are many examples of work system difficulties related to mismatch with organizational culture (part of the environment) and many other examples of work system stoppages due to failures of infrastructure, another of the nine elements. This is not about dependent and moderating variables. This is about whether each of the elements of the work system framework can be applied usefully for understanding managing, and improving typical examples of work systems.

Furthermore, the claim that a nine-element framework is useful is not a claim that other ideas are not useful or that the entire framework must be used at all times. WSM is based on WST. The first step in most WSM analysis templates is to name the work system in a single verb phrase. That doesn't say much, but it helps in clarifying what system is being analyzed. A subsequent step is to create a one-page summary of the "as is" work system using only the six central elements of the work system framework and not using the other three elements. The other three elements are useful for the complete analysis, but do not need to be mentioned at the beginning of the analysis. Other types of information and levels of detail are included as the analysis proceeds. This is not about dependent, moderating, and independent variables. It is about providing a cognitively manageable system view of a work system without leading users to become overwhelmed in the myriad of details that might be mentioned.

What are criteria for evaluating WST? N\&M (p. 351-354) discusses how WST would fare if evaluated using five criteria for a Type 4 theory, importance, novelty, parsimony, level of theory, and falsifiability. The WST article, pp. 94-97, evaluated WST based on the first two of those criteria, relevance (importance) and novelty, plus two other criteria, clarity and usefulness for teaching, research, and practice. N\&M's suggested criterion of parsimony makes sense in relation to a Type 4 theory but is far less interesting in relation to WST, whose actual use calls for zooming in and out between different levels of description that include different concepts (e.g., see the work system metamodel, Figure 2 in Section 5). The criterion of falsifiability fits a Type 4 theory but simply does not fit WST or other system theories. WST need not be falsifiable any more than systems analysis and design in general needs to be falsifiable or structuration theory needs to be falsifiable. WST consists of a definition and two frameworks that have been used describe and analyze a large number of situations. Since other approaches or tools might be better for that purpose, comparative usefulness is a much more valuable criterion than falsifiability.

Beyond this paper's scope is the broader question of how to evaluate abstract forms of knowledge that might include concepts, frameworks, theories, models, and methods. Alter (2014f) pursues an aspect of that topic by viewing WST and its extensions as conceptual artifacts (Bereiter, 2005) and showing how WST might fare in relation to a set of criteria for conceptual artifacts. Those criteria are broader and more inclusive than the five discussed by N\&M They include value, rigor, testability, parsimony, breadth of use, robustness, durability, generativity, and source. The criterion of generativity leads to the question of whether WST is becoming a platform.

\subsection{WST as a Platform for Research, Teaching, and Practice}


N\&M see WST as a theory, but at this point, four years after the first draft of the WST article and a year and a half after its publication, I see WST as more than a theory. I see it as a platform for many future applications and extensions in IS and within and across a number of disciplines. As a platform it has value when used directly, but also can be built upon in valuable ways, many of which may not be anticipated.

To visualize WST as a platform, consider the characteristics of platform design discussed by Hanseth \& Lyytinen (2010, p. 4) in relation to IT platforms such as MS Office, Windows, Linux, and SAP. "Platform designs draw upon architectural principles that organize IT capabilities into frameworks allowing the software to address a family of generic functional specifications that meet the needs of multiple, heterogeneous and growing user communities. ... A platform's initial design starts with a set of closed specifications determining included IT capabilities and anticipated requirements for their extensions and combinations. Their evolution is also governed and constrained by these initial specifications."

While orders of magnitude simpler and more limited in scope than IT platforms, WST provides a core of ideas (the three components of WST) that can be used for many diverse purposes. That core has sufficient clarity and scope to serve as a basis for developments that expand in different directions to address a variety of concerns. Some of those developments are organized around one of the two central frameworks in WST. Other developments introduce new ideas that initially may seem peripheral, but that can be used in conjunction with the central frameworks. An example is a "service value chain framework" (Alter, 2008, 2010d) that helps in understanding work system-related value creation. It does that by focusing on customer and provider responsibilities and on front stage and back stage activities, topics that do not appear in the three components of WST.

Examples in five overlapping categories of topics illustrate how WST can serve as a platform. The categories are as follows:

1) WST extensions related to work system operation, characteristics, and evaluation

2) Application of WST for understanding, analyzing, and designing systems in organizations

3) Linkage of WST and its extensions to concepts, models, and techniques for IT professionals

4) Use of WST for broader concerns related to the structure and dissemination of knowledge about systems

5) Diverse WST applications or extensions by researchers with diverse goals and interests.

Deferring examples to Section 5. To simplify this article's flow, examples under each of the five categories will be deferred to Section 5 . In combination, the many topics mentioned under the various categories suggest the possibility of a powerful, reasonably unified approach to important issues that have not been addressed in a unified way to date. An integrated platform for thinking about systems in organizations could support 
system-related research and practice and could contribute to IS/IT pedagogy that is much better than the current disjoined offerings.

A first article or several initial articles already exist for some of the topics under each category in Section 5. Some are speculative because research is only beginning. Overall, however, it is clear that many topics derived from WST ideas are internally coherent and have already proved useful in various ways. Examples include use by many hundreds of MBA or Executive MBA students in the United States, China, Vietnam, India, and possibly elsewhere, and by many researchers including non-trivial use or discussion in over ten PhD theses that I was not involved in.

\section{Previously Unexplained Background and Motivation of the WST Article}

N\&M (p. 350) contains a possibly surprising comment: "We find that WST's purpose per se is not entirely clear in its current formulation." Ignoring any unintended omissions or confusions in my writing, N\&M's question about the purpose of WST may stem from my intentional reticence about the reasons for trying to articulate WST and reasons for WST's positioning in relation to the nature of theory and other topics. This section fills in some of the details.

\subsection{Need for a Theory}

As I transitioned from writing IS textbooks to producing conference papers and journal articles related to work system ideas and WSM, I received a number of reviewer comments of the following types:

"This paper is interesting and probably valuable in some ways, but it is not based on theory and therefore should be rejected."

"This paper is merely practical and therefore should not be published."

"This paper seems to have some new ideas that might be valuable, but it should be rejected because it is justified based on conference proceedings and minor journals. Real contributions to knowledge need to be based on past publications in major journals."

I had never encountered such comments during 8 years of working in an innovative and successful software firm or in feedback about 4 editions of an IS textbook. Since when do new ideas need to be based on a theory - preferably a theory that someone else developed years earlier and published in a reputable journal? In addition to implying that no one has the right to develop a totally new idea, that view seemed contrary to the way most new ideas are actually created, developed, and disseminated in the real world.

The clinchers were two journal submissions that were dismissed for different reasons. An article about a potentially useful relationship between work system snapshots and use cases was dismissed as atheoretical. The lack of theory seemed more important to the reviewer than the potential value of ideas related to a significant pedagogical and practical problem. A different article about thinking of systems in service terms was rejected by a reviewer partly because one of the central frameworks in the article had been published in what the reviewer considered an untrustworthy outlet - IBM Systems 


\section{Journal.}

The implications seemed obvious to me. Paraphrasing the title used by N\&M, "moving the work system approach forward" at more than a snail's pace required attaining a higher acceptance rate of future research related to work system ideas and WSM. That would require a broadly recognized theoretical basis for those ideas. In other words, it seemed to me that finding or articulating a theory related to work system ideas and WSM was a possible approach for solving a paper acceptance problem rather than a scientific problem related to the situations studied. Almost any plausible theory would suffice as long as it made sense in relation to work system situations and was published in a respected journal. An attempt to figure out whether general system theory would suffice led to a somewhat inconclusive article about that possible relationship (Alter, 2007). Since no existing theory that I knew about provided a convincing basis for work system ideas and WSM, I decided to try to develop something called work system theory. Even though I had thought a great deal about work systems and IS, I was not sure what WST should be.

After many false starts, I wrote a first draft of what eventually became the WST paper and brought it to the JAIS Theory Development Workshop at ICIS 2010. The reactions noted in different ways that the draft covered a lot of material related to work systems but was unwieldy, unfocused, and did not provide a clear definition of WST. Those observations were a good reflection of the state of my thinking about WST at that time, when I viewed it as an evolving combination of disparate ideas for understanding, analyzing, and designing systems in organizations. One workshop participant suggested that I should just write a book. I didn't want to do that because journal articles are more accessible than books and because journal articles seem to be the most recognized type of contribution in the academic IS discipline.

Luckily, Shirley Gregor, who was then Editor-in-Chief of JAIS, saw potential in the topic and volunteered to serve as SE for the article. I produced a new manuscript that incorporated some of her initial suggestions and she engaged highly qualified reviewers who were interested in the topic. The reviewers provided lengthy reviews that addressed a wide range of topics but left me uncertain about what to do next because I agreed with some points, disagreed with others, and simply didn't know how to respond to other points. Reading the reviews a number of times was part of a meandering path toward a moment when I recognized the distinction between WST, WSM and the extensions of WST. I finally knew what WST was, but worried that did not have a journal-strength justification or packaging of that view of WST.

\subsection{Was the Development of WST a Design Science Research Project?}

Since design science research (DSR) is about establishing and applying a rationale for developing new ideas or instantiations, I decided to claim that the effort to develop WSM was in essence a DSR project even though it started around a decade before Hevner et al. (2004) was published. In effect, the components of WST would be positioned as a design theory that motivated the development of WSM. I found an MIS Quarterly article (Markus et al., 2002) whose argumentation might provide a model for a rationale for WST. I produced a ponderous introduction based on linkage between: 1) a kernel theory consisting of five characteristics of systems thinking performed by business professionals in relation to systems in organizations, 2) a related set of four requirements for methods supporting system thinking by business professionals and 3) a set of six principles for analysis and design methods for business professionals, which in 
combination should lead to a set of effective concepts and methods for thinking of systems in organizations as work systems. The formulaic result was a cumbersome, lengthy, and totally artificial rationale that tried to overcome the "chicken and egg" problem of how the development of WST could qualify as a design science research project. In other words, a mass of verbiage tried to justify the claim that WST could be the basis of WSM even though it wasn't articulated as WST until a decade after the first versions of WSM were produced and used.

Responding to that draft, one of the reviewers who seemed enthusiastic about the importance of the paper's subject matter was still dissatisfied ...

"The first twelve pages were really "slow going" for me. Then, on page 13, I saw something that allowed me to start putting together the paper's argument in a way I could readily grasp: a diagram of the work system framework."

I immediately understood what to do. I would eliminate all of the DSR packaging and argumentation and would replace it with something very simple: "WST is not presented here as a design theory even though it has been used as the basis for proposed improvements in many hundreds of work systems. WST emerged as a byproduct of research that started long before scholars recognized the current tenets of design science. ... The development of WSM was guided by the essence of WST, which was not articulated as a theory separate from WSM during the first decade of research." (WST article, p. 75)

Eliminating the artificial justification allowed the paper to proceed to the main points before the reader lost patience. Instead of slogging through an elaborate after-the-fact rationale, the reader could move directly to the main content, and could evaluate it based on whether it seemed clear, internally consistent, and valuable.

\subsection{Back to N\&M's Question about WST's Purpose}

As mentioned earlier, N\&M found "that WST's purpose per se is not entirely clear in its current formulation." Ironically, the effort of developing and publishing the WST article had the purpose of moving the work system approach forward even though that purpose could not be stated explicitly.

The purpose of WST. The purpose of WST is the same purpose that the work system approach had for over well over a decade. In a sentence, WST's purpose is to serve as an organized kernel of ideas for understanding how systems in organizations operate and how they change over time, regardless of whether IT plays a significant role.

The purpose of the WST article. The purpose of WST is different from the purpose of the WST article. The original purpose of the article was to overcome obstacles that made it difficult to publish new developments related to work system ideas and WSM. In other words, the beneficial effort of clarifying the scope and details of WST started as an attempt to legitimize work system ideas and WSM by the fact that they were based on a theory.

Despite that inauspicious intention, the lengthy effort of organizing and clarifying ideas that existed in various variations for over a decade already has had many benefits, which is why I greatly appreciate the perseverance of the SE and reviewers in pushing me to produce something coherent. The 3-part definition of WST makes it possible to 
explain WST in a 20-minute presentation that includes the difference between WST and the various versions of WSM. Having a clear definition of WST makes it much easier to understand how WST supports a wide range of applications and extensions. Also, it is much easier to explain how WST and WSM are related to other theories and methods.

\section{Conclusions and a Question about the Primacy of Theory}

This response to N\&M covered a range of topics related to different views of what WST is, different views of how to "move WST forward", and background about why WST was called a theory in the first place. This conclusion returns briefly to the question of what is the best path for moving WST forward. It ends by questioning the academic IS discipline's commonly held belief that theory is better than other types of knowledge.

\subsection{What is the Best Path for Taking WST Forward?}

This article's response to N\&M addresses an implied suggestion in N\&M, pp. 350-351, that a beneficial direction for improving WST would convert it into a Type 4 theory. This article argues for a quite different approach.

Extending WST as a system theory. WST is a system theory that provides a basis for systems analysis and design methods. Converting WST into a Type 4 theory would change its nature totally and would eliminate most of its potential value, its applications in WSM and elsewhere, and most or all of its extensions. Of course it would be good to have a powerful theory for predicting the success of IT-related interventions or for demonstrating that the use of WSM or any other plausible method increases the likelihood of success for system-related projects. Even if that new theory could be formulated, however, calling it WST would only increase the confusion about WST vS. WSM vs. extensions of WST that the WST article addressed clearly for the first time.

Beyond responding to suggestions in N\&M, this article explains my view of how to attain greater value from WST by emphasizing its nature as a system theory. A direct path for attaining greater value from WST calls for increasing its range of application, and developing new extensions, even to the point of seeing WST as a platform for many future developments. Section 5 will flesh out that idea by identifying many WST-related topics that are being pursued or might be pursued under five categories. Deferring these topics to Section 5 permitted a smoother flow of ideas in the direct response to N\&M in the first four sections.

The backstory. Contrary to typical norms of academic publishing, this response also provided a backstory that revealed more than purely "scientific" concerns. The backstory explained why WST was called a theory instead of something else and why the WST article did not position the development of WST as a DSR project. Ironically, the purpose of the WST article was directly related to the title of N\&M, "Moving the Work System Theory Forward."

I leave it to the reader to decide whether the WST article's definition of WST as a theory was a scientific misdeed, an instance of opportunistic or manipulative behavior, or a typical example of the kind of positioning and packaging that is necessary for bringing new or different ideas into an existing discourse that has established expectations and rituals. Calling WST a theory and minimizing references to DSR pursued a combination 
of three goals: 1) a "scientific" goal of clarifying ideas and encouraging progress related to understanding systems, 2) a publishing goal of overcoming obstacles that were blocking the scientific goal, and 3) a community goal of attaining greater benefit from WST by making it known to more researchers, instructors, and perhaps even practitioners.

\subsection{Are Theories Better than Other Forms of Knowledge?}

The academic IS discipline sometimes seems to operate as though knowledge is divided into higher and lower forms of knowledge, where theories, especially Type 4 theories, are the higher forms and other types of knowledge such as information, concepts, frameworks, methods, and models are the lower forms. Consistent with an article titled "Is theory king?: questioning the theory fetish in information systems" Avison \& Malaurent (2014), it is not obvious why theory deserves such high status in an applied discipline like IS.

Most IS practitioners are not theoreticians. In practice, conscious reliance on explicit theories, especially Type 4 theories, is much less present than reliance on information, concepts, frameworks, models, and methods. For example, Ramiller \& Pentland (2009) argue that a key problem with IS research is its focus on variables instead of "actors, their actions, and the artifacts they use to accomplish those actions." (p. 475)

It is noteworthy that recognition of the most important contributions in many disciplines often are not specifically for theories or theorizing. Here are three examples:

A Nobel Prize lecture. The third section of the 2009 Nobel Prize Lecture by the economist Elinor Ostrom was titled, "Developing a Framework for Analyzing the Diversity of Human Situations" The term framework was in the section title because much of her work was based on the IAD [Institutional Analysis and Development] framework.

"The IAD framework is intended to contain the most general set of variables that an institutional analyst may want to use to examine a diversity of institutional settings including human interactions within markets. .... A specific theory is used by an analyst to specify which working parts of a framework are considered useful to explain diverse outcomes and how they relate to one another.... Models make precise assumptions about a limited number of variables in a theory that scholars use to examine the formal consequences of these specific assumptions about the motivation of actors and the structure of the situation they face. (Ostrom, 2010 p. 414).

Viewing theories as an intermediate step between frameworks and models is quite different from assuming that theories should reign over the other two.

Prominence of methods rather than theories in Nobel Prizes in physics, chemistry, and medicine. "There is a much greater frequency of Nobel science awards for contributions to method than for contributions to theory, [as shown by] an analysis of the last two decades of Nobel awards in physics, chemistry, and medicine. The available documentation of Nobel awards reveals two forms of method-theory synergy: (a) existing theories were often essential in enabling development of awarded methods, and (b) award-receiving methods often generated previously inconceivable data, which in 
turn inspired previously inconceivable theories." (Greenwald (2012, p. 99) "82\% of the contributions for the 21 -year period were for method, and $18 \%$ were for theory." (Greenwald, 2012, p. 103)

Turing Award for concepts, not theory. The computer scientist Leslie Lemport received the 2013 Turing Award, the most prestigious award in computing, "for fundamental contributions to the theory and practice of distributed and concurrent systems, notably the invention of concepts such as causality and logical clocks, safety and liveness, replicated state machines, and sequential consistency." (ACM, 2013) In a modest comment, Lemport said, "although I didn't create a theory, I did, with the help of others, create a path that other people have since followed-and turned into a superhighway." (McGoneal, 2014)

In my opinion (surely is not shared by part of the IS community), the academic IS discipline's elevation of theory above other types of knowledge stems from a combination of tradition, training, academic politics, physics envy, and other factors that are not substantively related to maximizing its real world impact. I think there is little evidence that privileging theory over other types of knowledge is beneficial, especially at a time when managers and executives often seem overwhelmed by the speed of technological and social change.

Arguments for the primacy of theory sometimes quote Lewin's (1951) statement that "there is nothing so practical as a good theory". In my experience there is also nothing so practical as a good framework or a good method or a good platform.

\section{Examples of Research Topics that Use WST as a Platform}

As introduced at the end of Section 2, this section identifies potentially fruitful research topics that are directly related to WST and/or its applications and extensions, These potentially fruitful research topics all pursue the spirit of moving WST forward. The topics are organized under each of five categories. The main point is that WST is not an end in itself. It is a possible steppingstone toward applications and extensions in many high-value areas. Like many first steps motivated by long-term hopes and intentions, some of these potential directions might seem like intuitive leaps that cannot be "justified" in a way that many journal reviewers would find acceptable, i.e., by constructing an artificial path through past research that may or may not have served as an inspiration or genuine justification. Appendix 2 at the end of the WST article presented hints at some of the topics mentioned here. Other topics are the result of more recent thinking and therefore identify possibilities that were not mentioned in the WST article.

\subsection{WST Extensions Related to Work System Operation, Characteristics, and Evaluation}

All of the following are extensions of WST rather than changes in the core of WST. Distinguishing between the core and the extensions is important for an evolving body of concepts, frameworks, and theories because it helps in understanding what is central, what is peripheral, and how all of the ideas form a unified whole. 
Work system principles. Alter (2004) proposed 21 work system principles (based partly on sociotechnical principles of Cherns (1976) that were organized using the work system framework. Those principles were compiled to help in the analysis and design of systems in organizations. Alter \& Wright (2010) evaluated a slightly expanded list of 24 principles based on opinions of six small cohorts of Executive MBA students. The data concerned the extent to which they believed that each principle should apply to most work systems in their organizations (average score around 6 out of 7) and the extent to which they believed that the operation of most of the work systems in their organizations seemed to conform with each of the 24 principles (average score around 4.5 out of 7 ).

Work system design spaces. A series of design spaces for thinking about possible improvements in work systems was proposed to help MBA and Executive MBA students think about possible improvements to systems in organizations. A sociotechnical design space can be defined as an organized, interrelated set of factors or topics that are amenable to design, that frequently affect system performance, and that therefore should be considered during the process of sociotechnical design. (Alter, 2010b) The design spaces were organized based on the elements of the work system framework plus a tenth category, "work system as a whole". As noted in the WST article (p. 88), the respective design spaces focus on topics such as possible changes in each element, characteristics of each element, risks related to each element, alternative locations of knowledge in a work system, and so on. For example, scalability, flexibility, and resilience are characteristics of a work system as a whole, whereas skills and incentives are characteristics of work system participants in the design space that focuses on work system characteristics.

Work system metamodel. Figure 2 is the fifth version of a metamodel that reinterprets elements of the work system framework to support more detailed analysis and design of work systems than is supported directly by the work system framework. The first version was proposed in Alter (2010a). A subsequent version adapted for service systems appeared in an article in Service Science (Alter, 2012a). The fourth version appeared in conference and workshop articles related to the following topics: a unified, operational view of service and service systems (Alter, 2014a); encouraging beneficial directions in emergent change (Alter, 2014b); and design thinking in IS (Alter 2014c). One of the fifth version's incremental improvements was greater clarity about the different types of informational entities that might be used, created, or updated by a specific work system activity. Another incremental improvement is mentioned in relation to the next research topic.

Visualizing and analyzing service systems as work systems and work systems as though they provide services. IBM, HP, Cisco and other technology companies supported a cooperative attempt to develop a science of services that might help in developing their businesses. (e.g., Chesbrough \& Spohrer, 2006, Spohrer et al, 2007). Alter $(2008,2010 d)$ introduced a service value chain framework that could be used in conjunction with the work system framework to accentuate service-related ideas such as provider responsibilities versus customer responsibilities, the intensity of interactions between providers and customers, value capture by customers and providers, and ideas from service blueprinting (Bitner et al., 2008) such as onstage and back stage activities, line of interaction, and line of visibility. The idea of "value blueprinting" (Alter, 2013d) goes a step further by combining the "value capture" concept with basic ideas from service blueprinting. In relation to service concerns, the additional contribution of the metamodel in Figure 2 involves establishing links between provider resources and value 
creation by customers. Those topics are of special interest to researchers who focus on the nature of service and service systems (e.g., they are mentioned in "foundational premises" in important articles on service-dominant logic (Vargo \& Lusch, 2004, 2008) that already have been cited thousands of times).

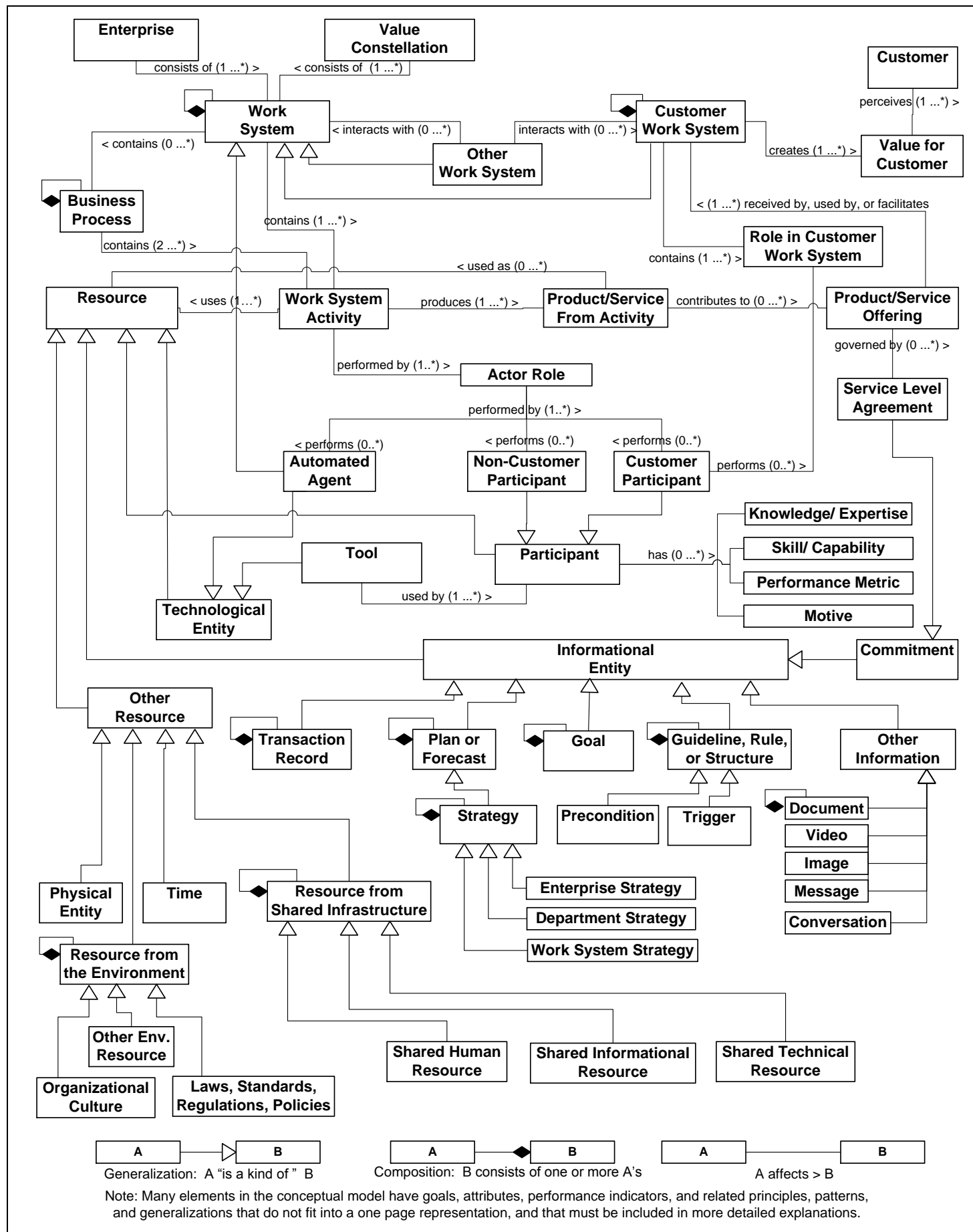

Figure 2. Work System Metamodel (version five) 
Concepts and metaphors related to specific types of subsystems. Current systems analysis and design textbooks say almost nothing about concepts and metaphors related to decision making, communication, sense making, sociality, and other aspects of systems in organizations that are relevant for understanding and improving work systems. That void might be addressed by viewing work systems as though they contain subsystems specifically devoted to decision making, communication, and other types of human activity and interaction. Alter (2013b) provides a step in that direction by identifying concepts and metaphors related to decision subsystems, communication subsystems, social subsystems, and other types of subsystems. Explicit consideration of the special nature of the different types of activities and/or subsystems could be extremely useful in understanding and analyzing work systems in which decision making, communication, sociality, and other specific types of activities are especially important.

Theory of workarounds. WST's work system life cycle model contains inward facing arrows that represent ongoing adaptations that occur endogenously from within the work system without external interventions or formal projects. Many of these adaptations are workarounds or are based on learning from workarounds. Curiosity about the nature of those adaptations led to developing a theory of workarounds (Alter, 2014e) based on hundreds of descriptions of workarounds found through secondary sources. Ideas from that effort were used by Röder, et al. $(2014 a, 2014 b)$ in relation to empirical research related to workarounds.

Taxonomy of work system interactions. Interactions between work systems may involve any of the elements of either interacting work system. For example, interaction between some work systems may cause problems related to double booking of work system participants, whereas interactions between other work systems may cause problems related to inconsistent data definitions. Designed interactions between work systems such as supplier-customer relationships are essential for work system operation. Unplanned, indirect, or accidental interactions of various types may have a variety of impacts. Alter (2010c) introduces an initial taxonomy of work system interactions that spans planned, unplanned, indirect, or accidental interactions involving any or all of the elements of the interacting work systems. The taxonomy and underlying rationale can be developed much further. The inquiry in Alter (2010c) led to inclusion of the entity type "other work system" in the metamodel in Figure 2. A more developed taxonomy of system interactions potentially could support systems analysis and design by identifying and classifying some of the many ways in which the work system being analyzed or design might be affected by other work systems.

Concepts and theories related to work systems that cross multiple organizations. Winter et al. (2014) note that "many important work practices, routines, and digital artifacts occur outside of organizational containers; increasingly work is not cleanly encapsulated within a single organization's boundaries." (p.4). It proposes an updated sociotechnical framework (neo-STS) that recognizes how work and infrastructures may be distributed across multiple organizations, thereby requiring concepts such as multiencapsulation, complex relations among elements, multi-inheritance, and continual negotiation. (pp. 26-27).

WST and the work system metamodel might support these ideas in a number of ways. The WST article notes that "work system is a general case for thinking about systems in or across organizations." The special cases of work systems include information 
systems, supply chains (which cross organizations), projects (which often cross organizations), self-service work systems (which often cross organizations, as in ecommerce), and totally automated work systems (which also may cross organizations). (p. 77). The concept of value constellation (from strategy studies and marketing) is included in the work system metamodel in Figure 2 because work systems sometimes cross organizations. The metamodel's concepts of customer participant and customer work system provide a basis for clarity about the often muddy concepts of co-production and value co-creation. (Alter, 2014a). An agent-based simulation of a work system based on the metamodel would likely consider the fact that work system participants often participate in multiple work systems. Thus, there is some possibility that WST and the work system metamodel might support the research proposed by Winter et al. (2014).

Enriching WSM and extensions of WST by incorporating additional concepts and theories. The existing literature of IS and other disciplines provide a large number of concepts, frameworks, and theories that apply to most or all of the entity types and relationships in the metamodel in Figure 2. For example, TAM, the technology acceptance model (Venkatesh \& Davis, 2000) is directly relevant to the relationship between participants and tools in Figure 2. Other concepts and theories that can be associated with that single relationship might provide richer insights for analyzing or designing work systems, e.g., concepts and theories related to affordances (Leonardi, 2011I; Volkoff \& Strong, 2013) and Heidegger's concept of equipment (Riemer \& Johnstone, 2014). Similar possibilities apply to entity types and relationships throughout the metamodel.

\subsection{Use of WST for Understanding, Analyzing, and Designing Systems in Organizations}

To date, WST has been used in many classroom settings, although the extent of usage has never been tracked. Precursors of WSM appeared in introductory chapters in the second (1996), third (1999), and fourth (2002) editions of Addison-Wesley and Pearson Prentice Hall information system textbooks that were used by many thousands of students. Subsequent usage was evident from adoptions of Alter (2006). Based on many comments at conferences (and also based on occasional requests for help from students and instructors from many countries), it is clear that some introductory IS courses and systems analysis courses introduce the work system framework or aspects of WSM as a way to think about systems in organizations.

More intensive use of WST involves individual or group assignments in which students follow WSM guidelines in the form of a template to identify a problem or opportunity in a work system, perform an analysis, and explain why proposed changes to various parts of the work system should result in better work system performance. Most of the intensive use of WST/WSM has involved MBA and Executive MBA students, many of whom have strong business experience. As reported in Truex et al. $(2010,2011)$, that type of usage demonstrated that ideas in WSM can be used by business professionals. To date there have been no case studies or surveys about the use of WSM by business professionals in work settings not associated with coursework or research. On the other hand, based on comments from students it is clear that some of the undergraduate, MBA, and Executive MBA students who learned about WSTMSM have used aspects of it such as the work system framework and work system snapshots in real world practice. 
Unfortunately there have been no long-term follow-ups concerning the intensity and effectiveness of applications in WST/WSM in real world practice. WST has started to become visible in the corporate world (e.g., Mason, 2012), but is still is not well known there. Obviously the current state of adoption calls for extensive research related to teaching and application.

Understanding usage of WST in classroom settings. It is easy to introduce the work system framework in classroom settings. To support further application in teaching it would be useful to compile examples of WST usage in classroom settings and to assess the effectiveness of different teaching approaches. Getting students with little business experience to use those ideas with insight is difficult, but the same comment applies for getting those students to apply almost any non-mechanical conceptual material related to business situations.

There is an additional practical challenge in asking students or student teams to use WST for describing and analyzing work systems. Reading student papers and providing meaningful feedback requires more effort than grading typical tests or analyses of prepackaged case studies that the instructor is familiar with or for which teaching notes may exist. Compiling and analyzing instructor and student experiences with intensive use of WST/WSM might help in developing more efficient or effective approaches.

Developing new templates for using WST. Below are two examples of trying out new templates. I hope that use of many other templates will help in learning how to use WST most effectively and efficiently in classroom assignments.

Example 1 - the "business case template." For the last several years I used versions of a WSM template that I called a "business case template," i.e., guidelines for doing a quick analysis of a work system and producing a "business case" for improving it in a particular way. The course time for using this material is often too short to allow a convincing cost/benefit study, and many students do not have enough background to produce meaningful cost/benefit studies for situations that are not pre-packaged for them. Therefore I always try to emphasize that a real world decision about which changes to pursue should include costs, benefits, and risks of the related project even if the students won't have enough time to produce convincing estimates.

Example 2 - adding a new questionnaire. In a small Executive MBA class I tried out a new variation that added a four page questionnaire that encouraged teams to at least consider a large number of ideas that they easily could overlook, such as scalability, flexibility, incentives, knowledge, corporate culture, and so on. Student teams analyzing a particular work system of their choice had to check 1, 2, 3, or not applicable for over 100 topics that mostly came from the design spaces mentioned earlier ( 1 for no problem, 2 for minor problem, 3 for serious problem). Student feedback suggested that they found the questionnaire easy to use and useful for identifying issues that deserved discussion. Based on that result, I used the questionnaire with a larger group from a different country. I was surprised and pleased by creative ways in which several teams incorporated a summary of the questionnaire into their presentations.

Incorporating WST into agile development projects. An issue in many agile development projects is the lack of easily used methods for clarifying the business goals and scope before launching a sequence of incremental software improvements. At least one set of European researchers is considering a research project that uses a quick 
work system analysis as a lightweight front end to agile development projects. Part of the rationale is that some business professionals involved with agile projects seem to have no organized way to visualize how those projects are going to produce genuine improvements in business performance, rather than just producing software changes that someone wants.

Engineering for emergent change. The topic of emergent change in systems has been discussed in a variety of ways, e.g., Orlikowski (1996), Feldman \& Pentland (2003), Germonprez et al. (2011), Pentland et al. (2011). Ideally it should be possible to design IT-enabled work systems in a way that recognizes that emergent change will occur. WST and some of its extensions might contribute by explaining how workarounds occur (Alter, 2014e) and how work system design should try to identify and take into account foreseeable workarounds of repetitive types, such as when a group of users agrees to use one user account to save time or when transactions that would trigger control limits by dividing them into small transactions that would not trigger the control limits. (Alter, 2014g). As discussed in Alter (2014b), those ideas could contribute to ongoing European research efforts related to enterprise engineering (e.g., Dietz, 2011; Dietz et al., 2013)) and service engineering (e.g., Böhmann et al. 2014) by providing a way to consider how enterprise engineering and service engineering should account for the high likelihood of emergent change after initial implementation.

Supporting "design thinking" related to systems in organizations. Frequent calls for digital innovation assume that business people will be able to identify ideas that are the basis of a path toward innovation. It is possible that WST and its extensions such as work system design spaces could provide knowledge-based support for design thinking related to information systems. (Alter, 2014c)

Demonstrating that use of WST and its extensions increases the likelihood of project success. Most of the WST research to date was motivated by unverified assumptions about the potential benefits of using WST and its extensions. Validating those assumptions would require research demonstrating that using WST increases the likelihood of project success in real world projects. I think that is the essence of suggestions in N\&M that WST should be converted into a Type 4 theory directed at explanation and prediction.

Implementation of CRM is an area where research about increasing the likelihood of project success would be possible. The hypothesis would be that CRM projects organized around improving the performance of specific, clearly identified customerfacing work systems will lead to greater improvements in business performance than CRM projects simply organized around installing and using CRM software. Similar research could look at the implementation of other packaged software. The same general approach also could be used for analyzing the business impact of custom programming projects. All of that research would focus on the benefits of managing projects as work system improvement projects instead of thinking of them as IT projects, IS projects, or software projects. 


\subsection{Linkage of WST and Its Extensions to Concepts, Models, and Techniques for IT Professionals}

Although WSM was initially developed to help business professionals understand systems in organizations, there is great value in linking WST and its extensions to concepts, models, and techniques used by IT professionals. Establishing such links will make it easier to move from summary-level discussions to detailed descriptions of the type that IT professionals need for developing software.

Linking WST to use cases. In effect, a use case answers the following question: "which activities will use a technical artifact that is being built?" That is far from the best question to ask business professionals whose main concern is improving the efficiency and effectiveness of work systems containing human participants, not just users of technology. With a WST approach, the fundamental question is how to improve a work system, not how to clarify where a proposed artifact might be used. Greater clarity for business and IT professionals would come from describing the proposed work system and then using the metamodel to clarify which work system activities will use which ITbased tools. Future research could show the benefits of deriving use cases from instantiations of the metamodel. (Alter \& Bolloju, 2012).

Linking WST to BPM. The gap between managerial and technical perspectives on business process management (BPM) reveals a significant challenge for BPM practice and research. Consider, for example, differences in scope and emphasis between typical managerial BPM topics (organizational change, process organizations, TQM) and typical technical BPM topics (detailed modeling, programming techniques, high degree of abstraction, automated process control or discovery). WST and its extensions could help in addressing that gap through links between the managerial view outlined by the work system framework and the more detailed view from the work system metamodel (Alter, 2013c).

A possible contribution based on the metamodel could be a set of design patterns for different types of processes, including 1) largely unstructured creative processes (such as various types of design) that might use tools but that have no pre-specified sequence, 2) semistructured knowledge processes (such as medical diagnosis or legal analysis) that use tools and procedural knowledge but also have no pre-specified sequence, 3) workflow processes (such as invoice or reimbursement processing) that have a prescribed flow but may treat individual steps as black box subroutines whose details are unknown, and 4) highly structured processes such as pharmaceutical and semiconductor manufacturing, where both the workflow sequence and the details of each step must be specified and followed precisely.

Linking WST to modeling frameworks used by IT professionals. Alter \& Bolloju (2012) provides an example showing how WST and the work system metamodel could provide a front end to object-oriented analysis and design (OOAD). Potential benefits of this approach stem from focusing more fully on business and process issues before diving into concepts and notations that most business professionals do not understand. In another case, Alter (2014d) uses a standard Object Management Group (OMG) example to illustrate possible overlaps between WST and a modeling method called DEMO, Design \& Engineering Methodology for Organizations (Dietz, 1999, 2006). That exploration could be a step toward finding synergies between DEMO and WST and its extensions. The rigorous underpinnings of DEMO based on communication theories could provide guidelines for producing models of work systems that might lead to 
improved versions of WSM and possibly to new extensions of WST. From the other direction, such research might suggest avenues for making DEMO more accessible and usable by business professionals. Similar efforts could explore relationships between WST and a number of other tools and methods for IT professionals, including Archimate (Lankhorst et al., 2009), MEMO (Frank, 2002), semantic object models (Ferstl and Sinz, 2006), and e3 value (Gordijn \& Akkermans, 2003).

\subsection{Use of WST for Broader Concerns Related to the Structure and Dissemination of Knowledge about Systems}

WST and its extensions should support big picture understandings of systems in organizations, better appreciation of important details that business professionals should understand, and better collaboration between business and IT professionals. An ambitious version of that goal is to provide a language for discussing and understanding the operation and evolution of systems in organizations. An incomplete step in that direction was an article proposing "Sysperanto," an imagined language for talking about systems in organizations (Alter, 2005). Ideas in that article reappear in the design spaces mentioned earlier. Subsequent thinking includes the following:

WST as an area of overlap and conduit between different disciplines. As illustrated in Figure 3, there is a substantial area of overlap between various disciplines such as IS, operations management, industrial engineering, business informatics, service science, marketing, organizational behavior, and management. That area of overlap involves the operation and improvement of systems within and across organizations. While each discipline has its own areas of special concern (e.g., queuing theory in operations management and co-creation of value in service science), the area of overlap could be a conduit for overcoming intellectual silos that inhibit exchange between different disciplines. WST and some of its extensions inhabit the area of overlap, perhaps leading to opportunities to use or adapt WST in many different disciplines that already focus on related issues but use different vocabulary. 


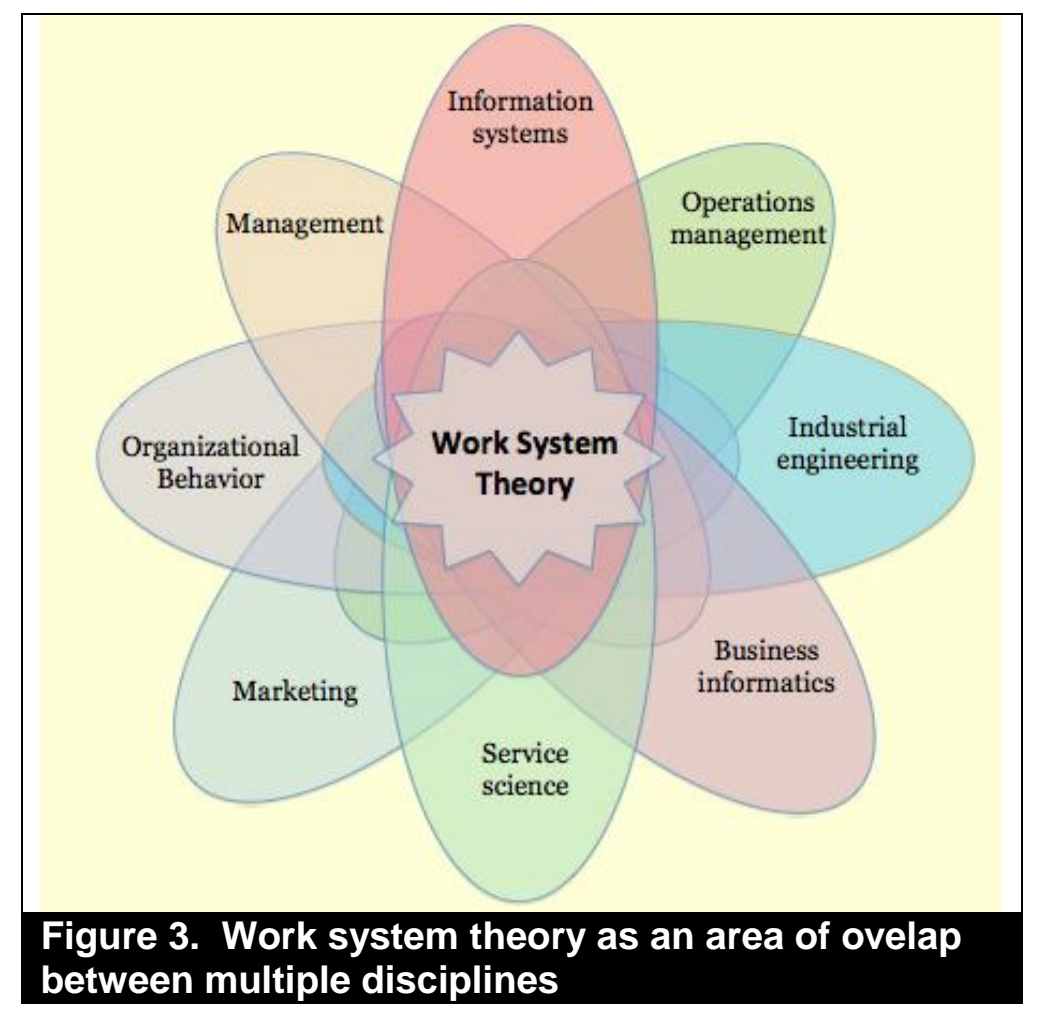

Scaffolding of a body of knowledge for work systems and IS. Alter (2012b) proposes a "knowledge cube" whose three dimensions are 1) work systems in general and the nine elements of the work system framework, 2) ten types of knowledge entities, such as nouns, verbs, adjectives, and generalizations 3) different special cases of work systems including work systems in general, information systems in general, supply chains, and projects. Many of the concepts that belong in cells for work systems in general are inherited by the special cases of work systems. One implication is that the search for native theories in IS (e.g., Straub, 2012) may bump into the fundamental issue that most of the concepts and knowledge that apply to information systems in general are actually concepts and knowledge about work systems in general. (Alter, 2012b, p. 12). A bit of evidence in that direction is that over half of the IS-related risk factors found in a study of IS risk (Sherer \& Alter, 2004) were actually risk factors for work systems in general, such as management support, staff competence, and appropriate incentives.

"Interpretary" for different views of systems. Alter (2013a) proposed the idea of an interpretary, a compendium of interpretations of common system-related terms from the viewpoint of different conceptual lenses (e.g., interpreting the terms system, requirement, and implementation based on a work system lens or a typical IT-centric lens). Development of an interpretary based on a WST lens, an IT-centric lens, and possibly other lenses could contribute to deeper understanding of advantages and shortcomings of specific systems analysis methods and might also help in the study of communication between business and IT professionals and its effect on business/IT alignment. 


\subsection{Diverse WST Applications or Extensions by Researchers with Diverse Goals and Interests}

N\&M notes that I have been involved in much of the research to date related to WST. I agree with that and find it gratifying that other researchers have applied WST or its extensions in research that I was not involved in at all and in areas where I have never worked. For example, in the year since its publication, the WST article has been applied in a diverse group of articles whose topics included high performance teams (De Leoz and Petter, 2013), alignment of business and application services (Rudzajs et al., 2013), education related to project management (Pirhonen, 2013), industrial product-service systems (Voigt et al., 2013), commentary on whether IS research is sociotechnical (Sarker et al., 2013), implications of academic service e-mobility (Basitt et al., 2013), comparison of different views of service and service systems (Cardoso et al. 2014), electronic currencies (Vitari, 2014), business process modeling for an emergency plan (Hamid et al., 2014), and transformation from product-centric to customer-centric services (Murthy \& Marjanovic, 2014). The breadth of these initial citations since the WST article was published in 2013 seems to imply that WST will prove useful in research on many topics by many authors.

\section{Acknowledgements}

I greatly appreciate that Fred Niederman and Sal March were interested enough to read my WST paper, think about what it meant to them, and produce a research perspective article that extends the discussion of WST. Their efforts introduced a new perspective on WST and (I hope) enriched the entire discussion of WST by providing an opportunity to respond.

I want to repeat my previous thanks to the WST paper's senior editor, Shirley Gregor, and to the reviewers who provided extensive comments and criticisms related to unbelievably long drafts of what remained an extremely long paper. Their patience and perseverance contributed directly because, perhaps paradoxically, the process of trying to respond to extensive reviews helped me clarify what I actually meant by WST.

I also want to thank Allen Lee, senior editor of the JAIS Research Perspectives section for his specific and insightful comments on two previous drafts of this article.

\section{References}

ACM (2013) A.M. Turing Award: Leslie Lemport http://amturing.acm.org/award winners/lamport 1205376.cfm

Alter, S. (2004) Making Work System Principles Visible and Usable in Systems Analysis and Design. Proceedings of AMCIS 2004, the Americas Conference on Information Systems, New York, NY, 1604-1611.

Alter, S. (2005) Architecture of Sysperanto: A Model-Based Ontology of the IS Field. Communications of the Association for Information Systems, (15)1, 1-40.

Alter, S. (2006) The Work System Method: Connecting People, Processes, and IT for Business Results. Larkspur, CA: Work System Press. 
Alter, S. (2007) Could the Work System Method Embrace Systems Concepts More Fully? Information Resource Management Journal, (20)2, April-June 2007, 3343.

Alter, S. (2008) Service System Fundamentals: Work System, Value Chain, and Life Cycle. IBM Systems Journal (47)1, 71-85.

Alter, S. (2010a) Bridging the Chasm between Sociotechnical and Technical Views of Systems in Organizations. Proceedings of ICIS 2010, the 31st International Conference on Information Systems.

Alter, S. (2010b) Design Spaces for Sociotechnical Systems. Proceedings of ECIS 2010, the 18th European Conference on Information Systems.

Alter, S. (2010c) Including Work System Co-Existence, Alignment, and Coordination in Systems Analysis and Design. Proceedings of the Sixteenth Americas Conference on Information Systems, Lima, Peru.

Alter, S. (2010d) Viewing Systems as Services: A Fresh Approach in the IS Field. Communications of the Association for Information Systems, (26)11, 195-224.

Alter, S. (2012a) Metamodel for Service Analysis and Design Based on an Operational View of Service and Service Systems. Service Science, 4(3), 218-235.

Alter, S. (2012b) The Knowledge Cube: Scaffolding for a Body of Knowledge about Information Systems. Proceedings of ECIS 2012, the 20th European Conference on Information Systems.

Alter, S. (2013a) An 'Interpretary' for the IS Discipline, a Compendium of Interpretations of Basic IS Concepts and Methods from Different Theoretical Perspectives. Communications of the Association for Information Systems: 33(18), 321-340.

Alter, S. (2013b) Incorporating More System-Related Knowledge into Systems Analysis and Design. Proceedings of the Nineteenth Americas Conference on Information Systems, Chicago, Illinois.

Alter, S. (2013c) Using Work System Theory to Link Managerial and Technical Perspectives on BPM. pp. 222-227 in Proceedings of the 2013 IEEE International Conference on Business Informatics, Vienna, Austria, July 2013, Springer.

Alter, S. (2013d) Value Blueprint and Service Design Space for Facilitating Value Creation. Proceedings of AMCIS 2013, the Nineteenth Americas Conference on Information Systems, Chicago, Illinois.

Alter, S. (2013e) Work System Theory: Overview of Core Concepts, Extensions, and Challenges for the Future. Journal of the Association for Information Systems, 14(2), 72-121.

Alter, S. (2014a) A Unified Operational View of Service, Service Systems, and Service Science, INFORMS Annual Meeting, Nov. 2014, San Francisco.

Alter, S., (2014b) Engineering Enterprises for Emergent Change. IEEE Conference on Business Informatics, $8^{\text {th }}$ TEE Workshop on Transformation \& Engineering of Enterprises, Geneva, Switzerland, July 2014

Alter, S. (2014c) Knowledge-Supported Design Thinking about Systems in Organizations: An Application of Work System Theory. DTBIS 2014: Workshop on Design Thinking in Business Information Systems, Tel Aviv, Israel.

Alter, S., (2014d) Potentially Valuable Overlaps between Work System Theory, DEMO, and Enterprise Engineering. WEETM 2014: 1st Workshop on Enterprise Engineering Theories and Methods, at IEEE Conference on Business Informatics, Geneva, Switzerland, July 2014

Alter, S. (2014e) Theory of Workarounds. Communications of the Association of Information Systems, 34(55), 1041-1066. 
Alter, S. (2014f) Why Should Theory Reign as King if the IS Discipline Wants More Impact in the Real World of Practice? SIG-PHIL workshop during ICIS 2014, Auckland, New Zealand.

Alter, S., (2014g) Workaround Design System, manuscript under consideration.

Alter, S. and Bolloju, N. (2012) A Work System Front End for Object-Oriented Analysis and Design. Proceedings of the $11^{\text {th }}$ Annual Symposium on Research in Systems Analysis and Design, Vancouver, Canada.

Alter, S. \& Wright, R. (2010) Validating Work System Principles for Use in Systems Analysis and Design. Proceedings of ICIS 2010, the 31st International Conference on Information Systems.

Avison, D., \& Malaurent, J. (2014). Is theory king? questioning the theory fetish in information systems. Journal of Information Technology, 18(4): 75-123

Basitt, U. N. A., Noor, N. L. M., \& Aljunid, S. A. S. (2013). Conceptualizing Academic Mobility e-Service through the Understanding of Service Relationships. Procedia Technology, 9, 371-380.

Bereiter, C. (2005). Education and mind in the knowledge age. Routledge.

Böhmann, T., Leimeister, J. M., \& Möslein, K. (2014). Service Systems Engineering - A Field for Future Information Systems Research. Business \& Information Systems Engineering, 6(2), 73-79.

Cardoso, J., Lopes, R., \& Poels, G. (2014) Service Systems Concepts, Modeling, and Programming. Springer. Cham, Heidelberg

Cherns, A. (1976) Principles of Socio-technical Design. Human Relations, (2)9, 783-792.

Chesbrough, H. \& Spohrer, J. (2006) A research manifesto for services science. Communications of the ACM, (49)7, July, 35-40.

De Leoz, G. M., \& Petter, S. C. (2013). Infusing High Performance Teams in Information System Work Environments, MWAIS 2013 Proceedings. Paper 12. http://aisel.aisnet.org/mwais2013/12

Dietz, J. L. (1999). Understanding and modelling business processes with DEMO. In Conceptual Modeling-ER'99 (188-202). Springer Berlin Heidelberg.

Dietz, J. L. (2006). The deep structure of business processes. Communications of the ACM, 49(5), 58-64.

Dietz, J. L. G., ed., (2011) Enterprise Engineering Manifesto. Jan. 2011, http://ciaonetwork.org/publications/EEManifesto.pdf

Dietz, J. L. G. et al. (2013). The discipline of enterprise engineering. International Journal of Organisational Design and Engineering, 3(1), 86-114.

Dwivedi, Y. K., Wastell, D., Laumer, S., Henriksen, H. Z., Myers, M. D., Bunker, D. \& Srivastava, S. C. (2014). Research on information systems failures and successes: Status update and future directions. Information Systems Frontiers, $1-15$.

Feldman, M.S. and Pentland, B.T. (2003) Re-theorizing organizational routines as a source of flexibility and change. Administrative Science Quarterly, 48, 94-118.

Feldman, M. and Orlikowski, W. (2011) Theorizing Practice and Practicing Theory, Organization Science. 22(5), 1240-1253.

Ferstl, O. K., \& Sinz, E. J. (2006). Modeling of business systems using SOM (347-367). Springer Berlin Heidelberg.

Frank, U. (2002). Multi-perspective enterprise modeling (memo) conceptual framework and modeling languages. In System Sciences. HICSS. Proceedings of the 35th Annual Hawaii International Conference on (1258-1267). IEEE.

Germonprez, M., Hovorka, D., and Gal, U. (2011) Secondary Design: A Case of Behavior Design Science Research. Journal of the Association for Information Systems, 12(10), 662-683. 
Gordijn, J., \& Akkermans, J. M. (2003). Value-based requirements engineering: exploring innovative e-commerce ideas. Requirements engineering, 8(2), 114134.

Greenwald, A. G. (2012). There is nothing so theoretical as a good method. Perspectives on Psychological Science. 7(2), 99-108.

Gregor, S. (2006) The Nature of Theory in Information Systems. MIS Quarterly, (30)3, 611-642.

Hamid, A., Rozan, M., Ibrahim, R., Deris, S., Nik Rushdi, H., \& Yunus, M. N. (2013). Business Process Analysis of an Emergency Plan using Work System Theory. Journal of Research and Innovation in Information Systems, 37-43, ISSN: 22891358

Hanseth, O., \& Lyytinen, K. (2010). Design theory for dynamic complexity in information infrastructures: the case of building internet. Journal of Information Technology, 25(1), 1-19.

Hevner, A., March, S. T., Park, J., \& Ram, S. (2004). Design science in information systems research, MIS Quarterly, 28(1), 75-105.

Lankhorst, M. M., Proper, H. A., \& Jonkers, H. (2009). The architecture of the archimate language. In Enterprise, Business-Process and Information Systems Modeling (367-380). Springer Berlin Heidelberg.

Larsen, K. R., Allen, G., Vance, A., Eargle, D. (Eds.) (2014). Theories Used in IS Research Wiki. Retrieved July 19, 2014 from http://istheory.byu.edu.

Leonardi, P. M. (2011) When Flexible Routines Meet Flexible Technologies: Affordance, Constraint, and the Imbrication of Human and Material Agencies. MIS Quarterly, (35) 147-167.

Lewin, K. (1951). Field theory in social science: Selected theoretical papers (D. Cartwright, Ed.). New York, NY: Harper \& Row

Markus, M.L., Majchrzak, A., and Gasser, L. (2002) A Design Theory for Systems that Support Emergent Knowledge Processes. MIS Quarterly, (26)3, 179-212.

Mason, L. (2012) Improving application design to support natural change, Hewlett Packard Viewpoint Paper. October 2012, 1-10.

McGoneal, J. (2014) Leslie Lemport '60: Turing Winner Loves to Solve Practical Problems, MIT News Magazine. Aug. 19, 2014

Murthy, V., \& Marjanovic, O. (2014). Understanding a Transformation Process from Product-Centric to Customer-Centric Services in a Financial Institution - A Work System Perspective. In Service Research and Innovation(29-43). Springer International Publishing.

Niederman, F. \& March, S. (2014) Moving the Work System Theory Forward, Journal of the Association for Information Systems. 15(6), 346-360.

Orlikowski, W. J. (1996). Improvising organizational transformation over time: A situated change perspective. Information Systems Research. 7(1), 63-92.

Ostrom, E. (2009). Beyond markets and states: polycentric governance of complex economic systems. (Nobel Prize Lecture), Workshop in Political theory and Policy analysis, Indiana University, Bloomington, in 47408, and Center for the Study of Institutional Diversity, Arizona State University, Tempe, AZ, USA.

Pentland, B. T., Haerem, T. and Hillison, D. (2011) The (N)Ever-Changing World: Stability and Change in Organizational Routines. Organization Science, (22)6, 1360-1383.

Pirhonen, M. (2013). Supporting the success of an information systems project: viewpoints on education and replacement of the project manager. Ph.D. dissertation, University of Jyväskylä 
Ramiller, N. C., \& Pentland, B. T. (2009). Management implications in information systems research: the untold story. Journal of the Association for Information Systems, 10(6), 2, 474-494.

Riemer, K., \& Johnston, R. B. (2014). Rethinking the place of the artefact in IS using Heidegger's analysis of equipment. European Journal of Information Systems, 23(3), 273-288.

Röder, N., Wiesche, M., \& Schermann, M. (2014a). A Situational Perspective on Workarounds in IT-Enabled Business Processes: a Multiple Case Study. Twenty Second European Conference on Information Systems, Tel Aviv 2014.

Röder, N., Wiesche, M., \& Schermann, M. (2014b). Why Managers Tolerate Workarounds - The Role of Information Systems. Twentieth Americas Conference on Information Systems, Savannah, 2014

Rudzajs, P., Kirikova, M., \& Strazdina, R. (2013, January). Configurative Alignment of Business and Application Services: A Work Systems Perspective. In Business Information Systems Workshops (100-111). Springer Berlin Heidelberg.

Sarker, S., Chatterjee, S., \& Xiao, X. (2013). How "Sociotechnical" is our IS Research? An Assessment and Possible Ways Forward. Thirty Fourth International Conference on Information Systems, Milan 2013

Schatzki, T.R. (2001) Practice Theory, 1-14 in Schatzki T.R., Knorr Cetina, K. and von Savigny, E. (eds.) The Practice Turn in Contemporary Theory. London: Routledge.

Sherer, S. \& Alter, S. (2004) Information System Risks and Risk Factors: Are They Mostly about Information Systems? Communications of the Association for Information Systems, (14)2, 29-64.

Spohrer, J., et al. (2007) Steps Toward a Science of Service Systems. IEEE Computer, 71-77.

Straub, D. (2012). Editor's comments: Does MIS have native theories? MIS Quarterly, 36(2), iii-xii.

Truex, D., Alter, S., and Long, C. (2010) Systems Analysis for Everyone Else: Empowering Business Professionals through a Systems Analysis Method that Fits their Needs. Proceedings of 18th European Conference on Information Systems, Pretoria, South Africa.

Truex, D., Lakew, N., Alter, S., and Sarkar, S. (2011) Extending a Systems Analysis Method for Business Professionals. European Design Science Symposium, Leixlip, Ireland, Oct. 2011.

Venkatesh, V., \& Davis, F. D. (2000). A theoretical extension of the technology acceptance model: four longitudinal field studies. Management science, 46(2), 186-204.

Vargo, S.L., \& Lusch, R.F. (2004) Evolving to a New Dominant Logic for Marketing. Journal of Marketing (68), 1-17.

Vargo, S. L., \& Lusch, R. F. (2008). Service-dominant logic: continuing the evolution. Journal of the Academy of Marketing Science, 36(1), 1-10.

Vitari, C. (2014). Electronic currencies for purposive degrowth? Grenoble Ecole de Management.

Voigt, B. F., Mänz, K., \& Wilkens, U. (2014). What Leadership Pattern can be Observed in IPS ${ }^{2}$ Work Systems when Compared with Production and Service? Procedia CIRP, 16, 277-282.

Volkoff, O., \& Strong, D. M. (2013). Critical realism and affordances: theorizing ITassociated organizational change processes. MIS Quarterly, 37(3), 819-834.

Weber, R. (2012) Evaluating and Developing Theories in the Information Systems Discipline, Journal of the Association for Information Systems. 13(1), 1-30. 
Winter, S., Berente, N., Howison, J., \& Butler, B. (2014). Beyond The Organizational 'Container': Conceptualizing 21st Century Sociotechnical Work. Information and Organization, 24(4), 250-269. 